\title{
Weather-dependent modelling of the indoor radon concentration in two dwellings using CONTAM
}

Indoor and Built Environment 2019, Vol. 28(10) 1341-1349

(C) The Author(s) 2019 Article reuse guidelines: sagepub.com/journalspermissions

DOI: $10.1177 / 1420326 \times 19841119$ journals.sagepub.com/home/ibe @SAGE

\author{
Javier García-Tobar (1)
}

\begin{abstract}
This study presents a methodology for including weather factors when simulating radon levels inside a dwelling using the CONTAM modelling software. The main purpose is the development of a reliable tool for assessing the various factors that affect radon concentrations, which would increase the possibility of improving indoor air quality. Indoor radon concentrations and weather data collected over six months are presented together with simulation results and compared both qualitatively and quantitatively. The methodology described should assist in simulating more realistic indoor radon concentration variations over a period of several months that can afterwards be used when designing homes with radon mitigation features.
\end{abstract}

\section{Keywords}

Radon, Modelling, Weather, CONTAM, Indoor air quality

Accepted: 11 March 2019

\section{Introduction}

Radon $\left({ }^{222} \mathrm{Rn}\right)$ is a radioactive gas produced in the uranium decay chain. Naturally occurring uranium can be found in soils and rocks such as granite, shale, phosphate and pitchblende. Uranium breaks down into radium, which then decays into radon. In its gaseous form, it can easily move up through the soil and into the atmosphere. It is an odourless gas and therefore impossible to detect without special equipment. Due to its radioactive nature, it represents the second leading cause of lung cancer, after smoking. ${ }^{1}$

Radon generation and transport are very complex processes whose interplay cannot be easily quantified or controlled, such as emanation, diffusion, advection, absorption and adsorption. ${ }^{2}$ There are too many variables that need to be accounted for; however, multizone indoor air quality and ventilation analysis computer programs such as CONTAM are able to provide valid results. ${ }^{3}$

As noted in previous studies, several observations related to factors influencing radon concentrations can be taken into account when analysing or mitigating radon problems in the home. ${ }^{4}$ One important factor is that the shorter the test duration, the greater the chance of a weather-compromised test result, ${ }^{5}$ therefore, radon measurements and simulation should be carried out over a long period of time and combined with closely following weather factors. Of the weather factors, it has been noted that declining barometric pressures are associated with increases in radon influx ${ }^{6}$ and lower radon concentrations correlate with small differences between indoor and outdoor temperatures.

Radon is soluble in water and dissolves into groundwater and can be transported some way from the source, ${ }^{7}$ therefore, radon levels are higher during torrential rain. The wind also influences radon levels; ${ }^{8}$ when it hits a home, it will either create a more positive indoor pressure that pushes the radon out or a negative

School of Mines, Polytechnic University of Madrid, Madrid, Spain

\section{Corresponding author:}

Javier García-Tobar, School of Mines, Polytechnic University of Madrid, 22 Constancia St., 28002 Madrid, Spain.

Email: jgtobar@iies.es 
indoor pressure that sucks more radon in. Finally, seasonal variations have a great impact on radon levels, ${ }^{9}$ which are typically higher during the winter months because heating systems pull air up and out of the home. When the ground is frozen, it creates a blanket effect that can trap radon in the soil around the house, which increases the amount of radon entering the home. ${ }^{10,11}$

The present study represents the continuation of two previous publications. ${ }^{12,13}$ The first paper ${ }^{12}$ investigated the indoor radon variations in two similar dwellings, one occupied by a single person and the other unoccupied, from the same residential building in Madrid. It showed that the radon level was slightly higher in the unoccupied dwelling than in the occupied one. From the analysis of recorded radon levels, it was found that a specific seasonal pattern existed in the indoor radon concentration. The second paper $^{13}$ presented a methodology for estimating radon levels inside the same dwellings as in the first study, using the CONTAM modelling software, with the main purpose of improving the indoor air quality by optimizing the mechanical ventilation. The generation rate of indoor radon sources was investigated in relation to the total surface of each room and compared with previous measurements. The weather factors were considered constant and dwellings were unoccupied.

The following recent studies have aimed at establishing terrain, geology and weather condition impact on radon concentration and the impact on human population in limited regions: Kowary, Poland ${ }^{14}$; Ulju County, Korea ${ }^{15}$; Kermanshah, $\operatorname{Iran}^{16}$; Beijing, China. ${ }^{17}$ Increased lung cancer occurrence in residents of Kowary, Poland, may be associated with increased concentrations of radon. ${ }^{14}$ The authors noticed an interdependence between increased atmospheric radon concentration and uranium content in soil, Kowary being situated near a spoil tip formed during uranium mining. High concentrations of radon are correlated with the presence of geological factors such as biotite granite. ${ }^{15}$ The indoor radon concentration increases with soil porosity. ${ }^{16}$ There are two main species of radon discharging from soil in active fault zones, including radon diffused and dispersed from permeable soil and upwelling from faults. ${ }^{17}$ The weather effects could play a significant part in dispersing radon, with a great impact on human health. The study concludes that appropriate protective measures should be put in place to protect inhabitants in buildings along the faults from emitted radon, and that the release of radon in the active fault zones should be assessed to determine possible risks.

A first systematic attempt to model air pollutants of noteworthy interest for human health using CONTAM, among which was ${ }^{222} \mathrm{Rn}$. This provided promising results but did not account for weather variations. ${ }^{18}$ The results indicated that the health burden from the investigated air pollutants varies, depending mainly on the generation rate and the duration for which an occupant inhales a certain pollutant. The doses calculated using CONTAM were found to depend on six partial parameters, among them the weather parameters, the indoor design of the zones of the dwelling, the location of the source of pollution and the size of the openings of the dwelling. The authors concluded that future work should extend the investigation to different scenarios of heating and pollutant transfer paths.

The aim of the present article is to develop a methodology for including weather factors when simulating radon levels inside a dwelling using the CONTAM modelling software, ${ }^{19}$ with the main purpose of developing a reliable tool for assessing the various factors that affect radon concentrations and improve indoor air quality. Correlations between weather factors and radon concentrations, both measured and simulated, were analysed and discussed in this article.

\section{Methodology}

\section{Modelling weather using the CONTAM software}

This article shows the influence of weather factors on radon concentrations within two similar dwellings assessed by a multizone modelling software for airflow and contaminant transport. The software used is CONTAM version $3.2,{ }^{19}$ developed by the National Institute of Standards and Technology (NIST); the first version was released in the year $2000 .^{20}$ The modelling used for the simulated dwellings is identical to the one described in the aforementioned study. ${ }^{13}$ The only difference being the modelling chosen for the windows: from a one-way flow using power law to a two-way flow. This was done in order to account better for wind effects; otherwise, the wind would have a negligible impact on the indoor radon concentrations.

This section describes in detail the methods employed for modelling weather data in CONTAM for extracting more realistic ${ }^{222} \mathrm{Rn}$ concentrations in the simulated dwellings. The flowchart shown in Figure 1 summarizes the steps required for the present simulation.

The parameters defining the outdoor weather conditions are defined through so-called 'ambient files'. Ambient files include weather (WTH extension), contaminant (CTM extension) and wind pressure and contaminant files (WPC extension). NIST has developed a software tool ${ }^{21}$ that allows any user to convert existing weather files to CONTAM 2.0 compatible weather files 


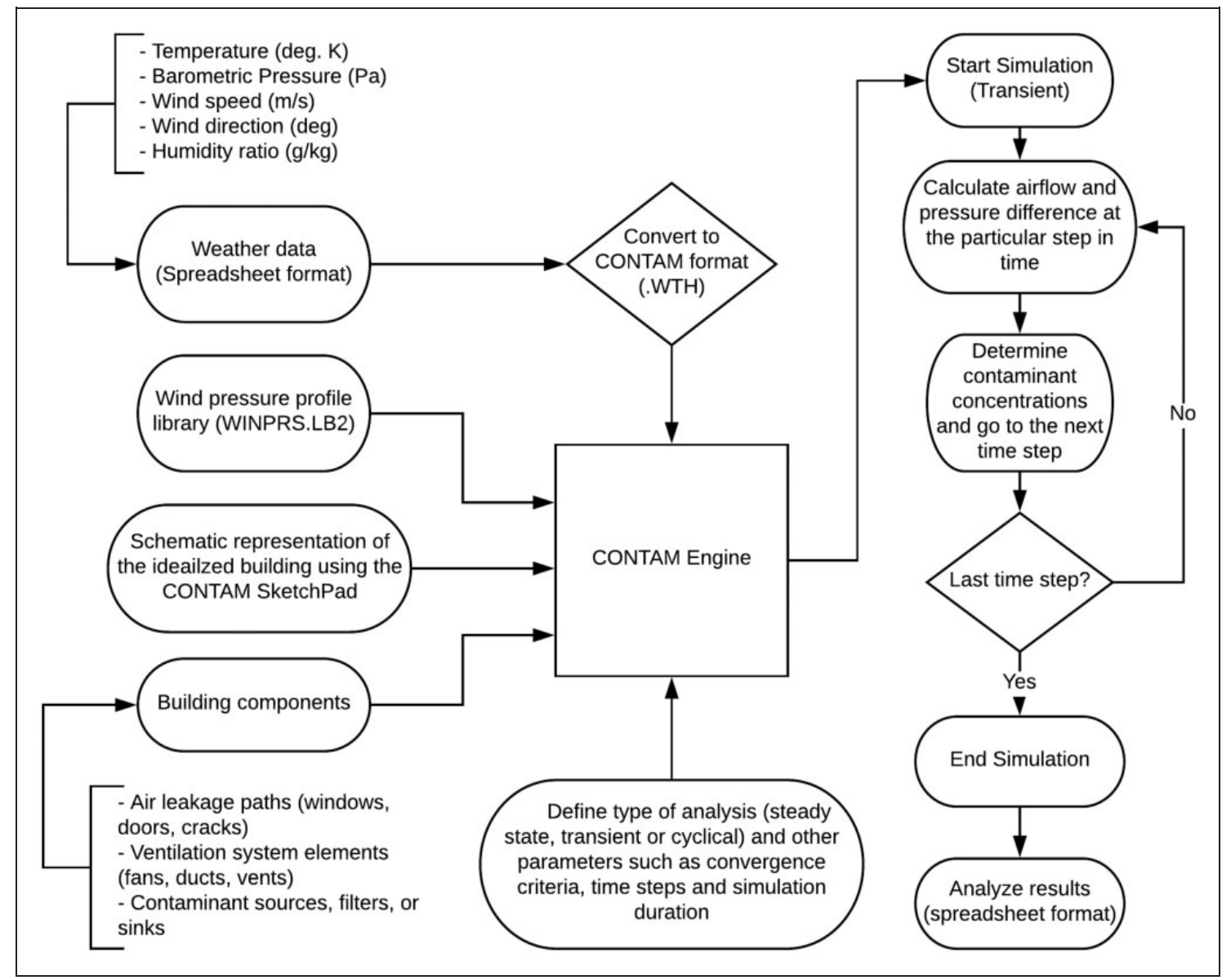

Figure 1. Flowchart showing the working principle of the present CONTAM simulation.

and also to output weather file templates that can be filled with measurements of weather data. A CONTAM weather file template was created for cases when the user has custom data to use in the weather file. A CONTAM weather file template is similar to a weather file in terms of format, but without the actual data. The user is required to fill the file with their own data using any spreadsheet editing program.

Ambient files may contain up to a year's worth of data and are used when performing transient simulations. They are ASCII files, but the formats are unique to CONTAM. ${ }^{14}$ Ambient weather conditions that impact building airflows as determined by CONTAM include temperature $(\mathrm{K})$, barometric pressure $(\mathrm{Pa}$, not corrected to sea level), wind speed $(\mathrm{m} / \mathrm{s})$, wind direction $\left({ }^{\circ}\right)$ and ambient humidity ratio (grams of $\mathrm{H}_{2} \mathrm{O}$ per $\mathrm{kg}$ of dry air). For steady-state airflow analysis, these userdefined values can be provided via the user interface.

In order to convert wind speeds (v) into pressures (P) on the exterior facade of a building being analysed, wind pressure coefficients (C) are required. These dimensionless coefficients are related to the wind pressure on the exterior facade by equation (1)

$$
P=\frac{C v^{2}}{2}
$$

The most reliable means of determining the value of $\mathrm{C}$ for a given building are through on-site measurements or wind tunnel studies. However, these studies can be expensive and unsuitable for generic buildings. Based on a number of field and wind tunnel studies, wind pressure data and coefficients are available. ${ }^{22}$ The wind pressure profile, representing a list of such wind pressure coefficients, corresponding to the angle between the wind direction and the building wall can be provided in CONTAM through the WINPRS.LB2 library. ${ }^{23}$ The present simulations use the profile 'TallRoof-1', corresponding to a tall building with a length/width ratio of 1 .

\section{Measurements}

Outdoor and indoor data were recorded every $3 \mathrm{~h}$ for a total period of six months between May and November 


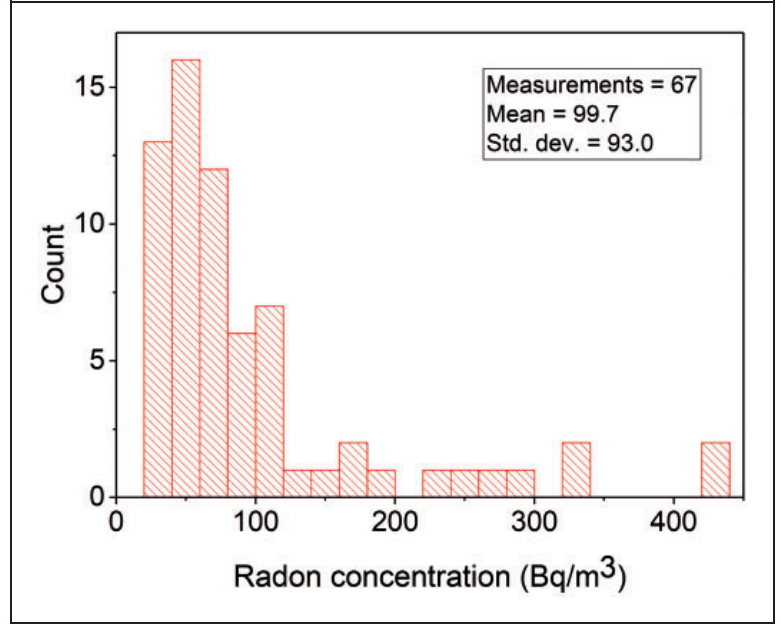

Figure 2. Frequency distribution of recorded radon concentration $^{12}$ in the region of interest for the present study.
2014 for two dwellings situated on the first floor in a residential building in the neighbourhood of Guindalera (in the district of Barrio de Salamanca, Madrid), with the approximate coordinates of latitude $40^{\circ} 26^{\prime} 24^{\prime \prime} \mathrm{N}$ and longitude $3^{\circ} 40^{\prime} 12^{\prime \prime} \mathrm{W}$. Throughout this article, the occupied dwelling was labelled with the letter ' $A$ ' and the unoccupied dwelling with the letter 'B'.

The survey was performed in a new building that consisted of three floors above ground and two below. The building is located in a radon-prone area, which was identified, in part, from the information given by MARNA (an acronym of 'MApa de Radiación gamma NAtural') $)^{24}$ and 'Radon Project $10 \times 10,{ }^{25}$ The second map divides Spain into $10 \times 10 \mathrm{~km}^{2}$ cells. Each cell has an average radon concentration based on indoor measurements. The building is located in cell M41. To give an idea of order of

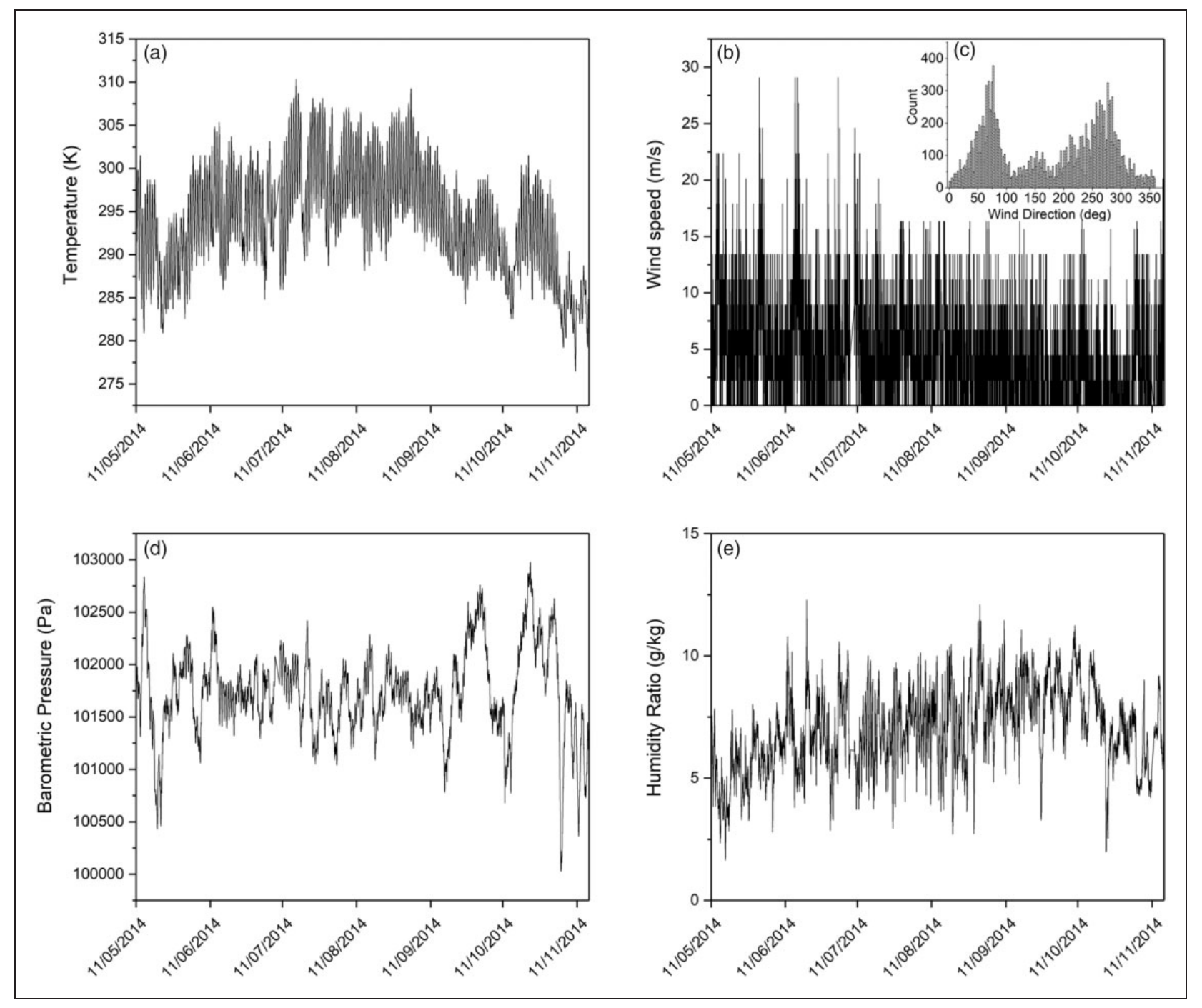

Figure 3. Outdoor measurements of temperature, barometric pressure, wind speed, wind direction and humidity ratio. 


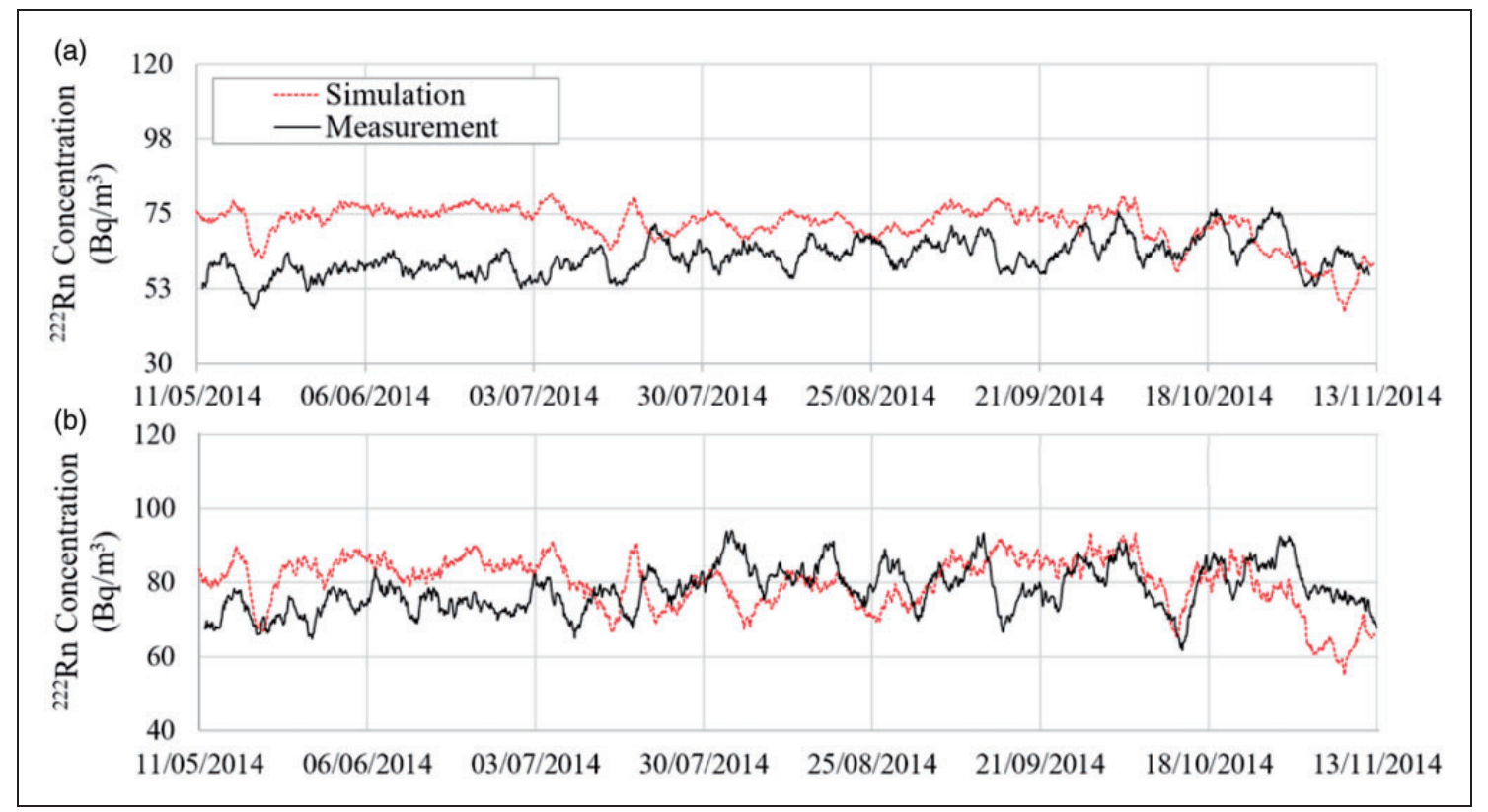

Figure 4. Simulated and measured indoor radon concentrations in dwellings A and B. A 72-h moving average was used in order to smooth out the data.

Table 1. Temperature (mean, maximum and minimum), rain and humidity in a station located in Madrid for the period 1981-2010.

\begin{tabular}{|c|c|c|c|c|c|}
\hline Month & $\begin{array}{l}\text { Mean } \\
\text { temperature }(\mathrm{K})\end{array}$ & $\begin{array}{l}\text { Maximum } \\
\text { temperature }(\mathrm{K})\end{array}$ & $\begin{array}{l}\text { Minimum } \\
\text { temperature }(\mathrm{K})\end{array}$ & Rain (mm) & Humidity (\%) \\
\hline January & 279.45 & 282.95 & 275.85 & 33 & 71 \\
\hline February & 281.05 & 285.15 & 276.85 & 34 & 65 \\
\hline March & 284.35 & 289.45 & 279.35 & 25 & 55 \\
\hline April & 286.05 & 291.35 & 280.85 & 45 & 56 \\
\hline May & 289.85 & 295.35 & 284.45 & 50 & 53 \\
\hline June & 295.35 & 301.35 & 289.25 & 21 & 44 \\
\hline July & 298.75 & 305.25 & 292.15 & 12 & 38 \\
\hline August & 298.25 & 304.45 & 291.95 & 10 & 41 \\
\hline September & 294.05 & 299.55 & 288.55 & 22 & 50 \\
\hline October & 288.25 & 292.55 & 283.85 & 60 & 64 \\
\hline November & 283.05 & 286.65 & 279.45 & 58 & 71 \\
\hline December & 280.05 & 283.15 & 276.75 & 51 & 74 \\
\hline Year & 288.15 & 293.05 & 283.25 & 421 & 57 \\
\hline
\end{tabular}

Note: A Vantage Pro Weather Station was used to record outdoor temperature, barometric pressure, wind speed and ambient humidity. These measurements are shown in Figure 3. The CONTAM weather template creator ${ }^{21}$ was used and the outdoor data were formatted according to the user guide. ${ }^{19}$

magnitude of the values, Figure 2 shows a frequency distribution of values contained in the M41 cell as of 2015.

The indoor radon measurements that were previously reported $^{12}$ were carried out with Sarad Radon Detectors. Radon monitors have a sensor to measure barometric pressure in addition to the temperature and humidity sensing elements. The average radon
Table 2. Mean values of simulated and measured radon concentrations in the two dwellings.

\begin{tabular}{lll}
\hline \multirow{2}{*}{ Dwelling } & \multicolumn{2}{l}{ Radon concentration $\left(\mathrm{Bq} / \mathrm{m}^{3}\right)$} \\
\cline { 2 - 3 } & Measurement & Simulation \\
\hline A & $62 \pm 5( \pm 8.5 \%)$ & $75 \pm 3( \pm 4.6 \%)$ \\
B & $78 \pm 6( \pm 7.8 \%)$ & $83 \pm 4( \pm 5.2 \%)$ \\
\hline
\end{tabular}


concentration recorded in the present survey, indicated in Figure 2, corresponds to the region with the highest frequency $\left(60-80 \mathrm{~Bq} / \mathrm{m}^{3}\right)$ in the distribution plot shown in Figure 2.

Under the Köppen climate classification, Madrid has a Csa climate, which is characterized by a dry summer and the coldest month averaging above $0^{\circ} \mathrm{C}^{26}$ The following table summarizes Madrid's typical monthly climate at an official meteorological station located in the city. Data were obtained ${ }^{27}$ using the reference period 1981-2010.

\section{Results and discussion}

The factors displayed in Figure 3 that had the most significant impacts on the radon concentrations were the wind speed and wind direction, followed by temperature (roughly a factor 10 weaker impact compared to the wind) and barometric pressure (an even lower impact than the variation induced by temperature). When varying solely the ambient humidity, the simulated radon concentrations remained constant, meaning that CONTAM does not consider the humidity variation in the airflow modelling.

Figure 4 shows the comparison between the 72-h moving average of the simulated radon concentrations and the measurements, for a period of six months (from 12 May 2014 to 11 November 2014) for both dwellings (A and $\mathrm{B}$ ). Moving average charts were used to smooth the data enough to reduce fluctuations so that the underlying trends are more apparent. All the weather factors mentioned above were taken into consideration. The Pearson (product-moment) correlation coefficient, ${ }^{28}$ usually represented by the symbol ' $\mathrm{r}$ ', is a measure of the linear correlation between two variables. It can have a value from -1 to 1 , showing correlation $(>0)$ and anti-correlation $(<0)$ between the different variables under analysis. It is also commonly used when evaluating the different factors that influence radon concentrations. ${ }^{29-31}$ The correlation strength can be assessed using the following generally established guidelines: ${ }^{28}$

$$
\begin{aligned}
& 0.1<|\mathrm{r}|<0.3-\text { small/weak correlation } \\
& 0.3<|\mathrm{r}|<0.5-\text { medium/moderate correlation } \\
& 0.5<|\mathrm{r}|-\text { large/strong correlation }
\end{aligned}
$$

Pearson correlation coefficients were calculated for the present simulated and measured datasets and the values 0.341 (dwelling A) and 0.198 (dwelling B) were obtained. These values indicate a low to moderate correlation between the simulated and measured datasets.

The values ${ }^{29-31}$ for the Pearson correlation coefficients corresponding to significant correlations are above 0.7 - therefore in the case of the present results, we cannot state any clear correlation between simulation and measurement. However, considering the mean values of the radon concentrations and standard deviations, shown in Table 2, the agreement is remarkable considering the number of factors involved in the simulation. The measured values are slightly lower than the simulated ones and the relative standard deviations are higher, suggesting that other factors that were not taken into account (e.g. precipitation, occupancy schedules) could be responsible for the larger variation of the measured values.

A downward trend in the radon concentrations in both measurement and simulation can be seen starting in October and November, when temperatures tend to drop. Analysing the evolution through the autumn period could bring an even better insight into the factors that influence radon concentrations. Standard meteorological values are provided in Table 1 to give an idea of the order of their magnitude. This

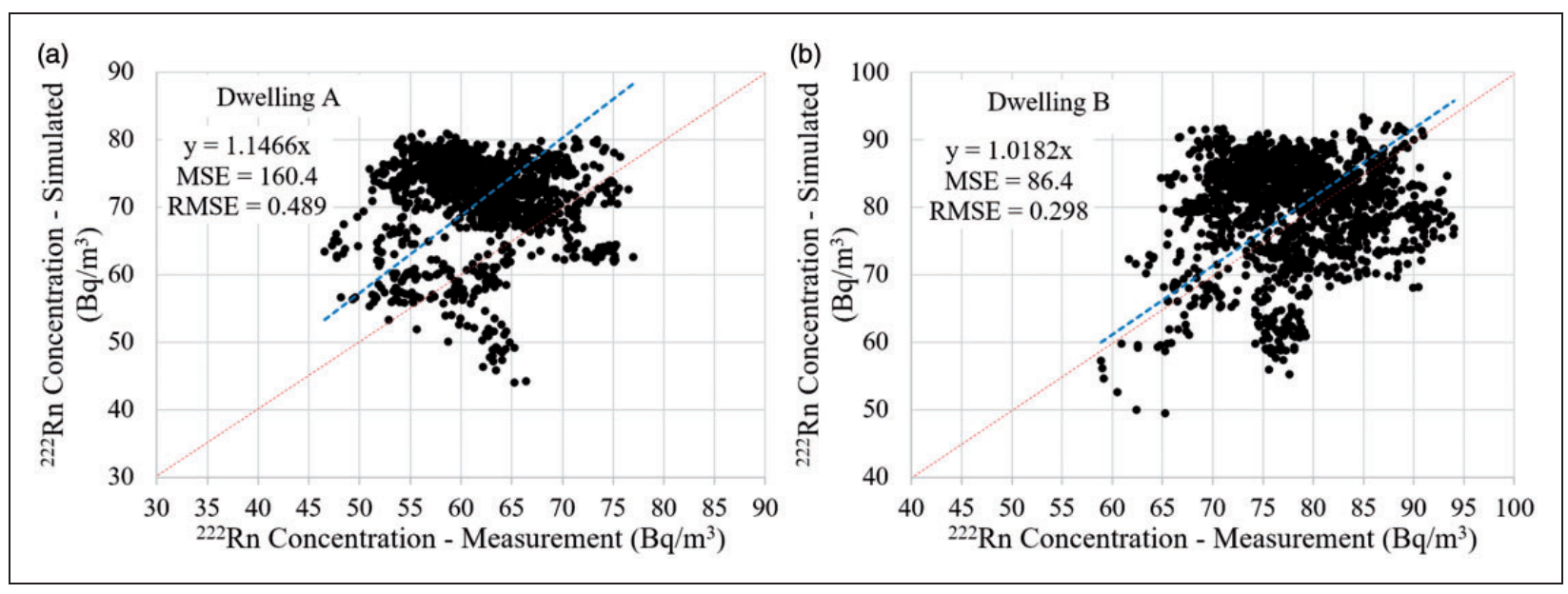

Figure 5. Correlation plots of simulated vs. measured indoor radon concentrations in dwellings A and B. 

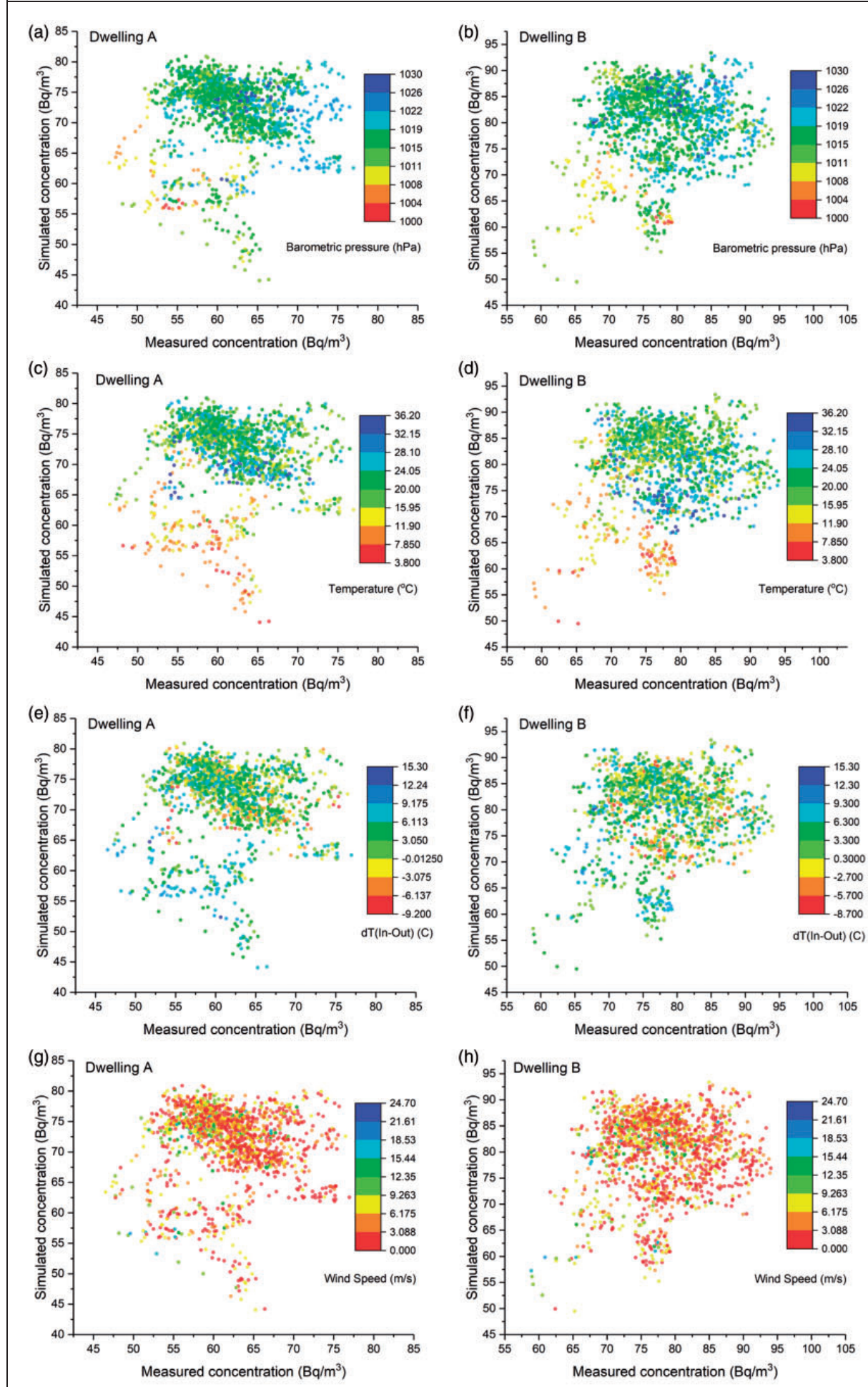

Figure 6. Correlation plots of simulated vs. measured indoor radon concentrations in dwellings A and B relative to the barometric pressure $(\mathrm{a}, \mathrm{b})$; temperature $(\mathrm{c}, \mathrm{d})$; temperature difference, $\mathrm{dT}$, between the indoor and outdoor temperature (e, f); and wind speed $(\mathrm{g}, \mathrm{h})$. 
observation prompts increased motivation for a more thorough study of radon concentrations and comparisons, with simulations following the methodology described in the present article for a full year and possibly including more dwellings in different buildings.

The Pearson correlation is only capable of detecting linear associations, so it is possible to have a pair of variables with a strong non-linear relationship and a small Pearson correlation coefficient. Therefore, scatterplots are mandatory for identifying if there are non-linear correlations. Figure 5 shows the correlation plots between the simulated and measured indoor radon concentrations. A perfect correlation is represented by the red dotted line, which is the $f(x)=x$ function. There is no indication of non-linear correlations, and the present simulated data show a reasonable agreement with measurements. However, there is room for improvement, considering that the mean squared error (MSE) has a value of 160 and 86 for dwellings A (occupied) and B (unoccupied), respectively. The occupation of a dwelling could significantly impact the airflow, due to the opening of doors and windows. The present simulations did not take into account of such actions, considering all the doors and windows were closed. The agreement may also improve if a future simulation takes rain into account as a weather factor. ${ }^{7}$ This is not yet possible in the present version of CONTAM. ${ }^{19}$

The correlations between different weather factors and radon concentrations were analysed qualitatively as colour-coded plots, shown in Figure 6. Barometric pressure, temperature, temperature difference between indoors and outdoors and wind speed are indicated in colour for each point corresponding to a measured vs. simulated value. It can be clearly seen that low/high barometric pressure, outdoor temperature or indooroutdoor temperature difference correlate with low/high radon concentrations, and these observations are reflected in both simulated and measured datasets. In the particular case of the two dwellings situated on the first floor, the influence of barometric pressure can be explained in a simple manner: the airflow is directed towards the region of low pressure and therefore pulls indoor radon outside. The influence of temperature is more complex and cannot be explained in a similar manner, as it is highly dependent on the soil type and building architecture. 7,9

In the case of wind speed, there is no clear relationship we can extract from the present data between high or low wind speeds and radon concentrations.

\section{Conclusions}

The present study has shown a good agreement between simulated and measured values of radon concentrations for two different dwellings in the same building when including weather factors such as outdoor temperature, barometric pressure, wind speed and wind direction. In the case of dwellings A (occupied) and B (unoccupied), the anthropogenic factors, such as opening windows and using the air conditioning system or the heat pumping system, did not seem to affect the periodic behaviour of radon. In the present study, the comparison between average simulated radon levels, considering unoccupied dwellings and measurements has also shown minimal differences, supporting the idea that the main variations of indoor radon levels are due to meteorological factors.

A clear correlation was established between low/ high barometric pressure, outdoor temperature or indoor-outdoor temperature difference and low/high radon concentrations, with these observations reflected in both simulated and measured datasets.

The methodology used for performing the simulations using CONTAM was presented in such a way that future studies can reproduce similar results for different dwellings and for longer periods of time. The present study's results suggest that other weather factors such as rain or building occupation, ventilation and heating schedules should be measured or determined in order to obtain more precise and realistic simulations that could assist in optimizing the indoor air quality of dwellings.

\section{Author's contribution}

Javier García-Tobar is the only contributor for this article.

\section{Acknowledgements}

The present study was a continuation of the research carried out by the author during the preparation of his thesis, titled 'Study of radon in dwellings using data mining models based on OLAP cubes' that was passed on 21 January 2016 by the Polytechnic University of Madrid (UPM). Figure 2 was created using data provided courtesy of LaRUC (The Radioactivity Laboratory of the University of Cantabria). The author also thanks the editor of this journal and two anonymous referees for their valuable comments.

\section{Declaration of conflicting interests}

The author(s) declared no potential conflicts of interest with respect to the research, authorship, and/or publication of this article.

\section{Funding}

The author(s) received no financial support for the research, authorship, and/or publication of this article.

\section{ORCID iD}

Javier García-Tobar (D) http://orcid.org/0000-0003-2348-1567 


\section{References}

1. World Health Organization (WHO). WHO handbook on indoor radon: a public health perspective Zeeb $\mathrm{H}$ and Shannoun F (eds). Geneva, 2009.

2. Rogers VC and Nielson KK. Multiphase radon generation and transport in porous materials. Health Phys 1991; 60: 807-815.

3. Musser A. Multizone modeling as an indoor air quality design tool. Olli Seppanen, Jorma Sateri (eds). In: Proceedings of Healthy Buildings, International Society of Indoor Air Quality and Climate, Espoo, Finland, 610 August 2000; 2: pp. 1-6

4. Curado A, Silva J, Carvalho L and Lopes S. Indoor radon concentration assessment in a set of single family houses: case study held in Barcelos, North of Portugal. Energy Proc 2017; 136: 109-114.

5. Scott AG. Effect of indoor radon variability on the duration and interpretation of radon measurements. In: Environmental Protection Agency (EPA) symposium on radon and radon reduction technology, EPA, Denver, Colorado, 17-21 October 1988.

6. Rigby JG and La Pointe DD. Wind and barometric pressure effects on radon in two mitigated houses. In: The 1993 international radon conference, American Association of Radon Scientists and Technologists, Denver, 20-22 September 1993.

7. Hoffinann RL. Radon contamination of residential structures: Impact of the "weather effect" on short-term radon test. In: The 1995 international radon symposium, American Association of Radon Scientists and Technologists, Nashville, 27-30 September 1995.

8. Riley WJ, Gadgil AJ, Bonnefous YC and Nazaroff W. The effect of steady winds on radon-222 entry from soil into houses. Atmosp Environ 1996; 30: 1167-1176.

9. Keskikuru T, Kokotti H, Lammi S and Kalliokoski P. Effect of various factors on the rate of radon entry into two different types of houses. Build Environ 2001; 36: 1091-1098.

10. Akbari K, Mahmoudi J and Ghanbari M. Influence of indoor air conditions on radon concentration in a detached house. J Environ Radioact 2013; 116: 166-173.

11. Sundal AV, Valen V, Soldal O and Strand T. The influence of meteorological parameters on soil radon levels in permeable glacial sediments. Sci Total Environ 2008; 389: 418-428.

12. García-Tobar J, Mazadiego LF and Quindós-Poncela LS. A comparison of preliminary results of indoor radon behaviour between one occupied and one unoccupied dwelling in Madrid, Spain. Solid State Phenomena 2015; 238: 140-150.

13. García-Tobar J. A comparative study of indoor radon levels between two similar dwellings using CONTAM software. Environments 2018; 5: 59.

14. Tchorz-Trzeciakiewicz DE and Kłos M. Factors affecting atmospheric radon concentration, human health. Sci Total Environ 2017; 584-585: 911-920.

15. Lee C, Choi S and Kim HR. Analysis radiation dose assessment of $222 \mathrm{Rn}$ in indoor air at schools: case study at Ulju County, Korea. Nuclear Eng Technol 2018; 50: 806-813.
16. Pirsaheb M, Najafi F, Hemati L, Khosravi T and Sharafi H. Data on the effect of geological and meteorological parameters on indoor radon and thoron level- case study: Kermanshah, Iran. Data Brief 2018; 18: 1945-1951.

17. Chen Z, Li Y, Liu Z, Wang J, Zhan X and Du J. Radon emission from soil gases in the active fault zones in the Capital of China and its environmental effects. Sci Rep 2018; 8: 16772.

18. Temenos N, Nikolopoulos D, Petraki E and Yannakopoulos P. Modelling of indoor air quality of Greek apartments using $\operatorname{CONTAM}(\mathrm{W})$ software. J Phys Chem Biophys 2015; 5:1-10.

19. Dols WS and Polidoro BJ. CONTAM User Guide and Program Documentation Version 3.2, Technical Note, NIST TN - 1887, Gaithersburg: NIST, 2015.

20. Dols WS, Walton G and Denton KR. CONTAMW 1.0 user manual, NISTIR 6476. Gaithersburg: NIST, 2000.

21. NIST CONTAM Weather File Creator, https://pages. nist.gov/CONTAM-apps/software/WEATHERprogram. htm (accessed 20 January 2019).

22. American Society of Heating, Refrigerating, and AirConditioning Engineers (ASHRAE). Handbook of Fundamentals. ASHRAE, Atlanta, GA, USA: Author, 1997.

23. Persily AK and Ivy EM. NISTIR 6585: input data for multizone airflow and IAQ analysis, www.nist.gov/el/ energy-and-environment-division-73200/nist-multizonemodeling/software-tools/contam/libraries (accessed 20 January 2019).

24. Quindós-Poncela LS, Fernández PL, Gómez Arozamena J, Sainz C, Fernández JA, Suarez Mahou E, MartinMatarranz JL and Cascón M. Natural gamma radiation map (MARNA) and indoor radon levels in Spain. Environ Int 2004; 29: 1091-1096.

25. Sainz-Fernández C, Fernández-Villar A, Fuente-Merino I, Gutierrez-Villanueva JL, Martin-Matarranz JL, García-Talavera M, Casal-Ordas $\mathrm{S}$ and QuindósPoncela LS. The Spanish indoor radon mapping strategy. Radiat Protect Dosimet 2014; 162: 58-62.

26. Agencia Estatal de Meteorología (AEMET). Iberian climate atlas. Air temperature and precipitation (1971-2000). Spain: AEMET del Ministerio de Medio Ambiente y Medio Rural y Marino, 2011.

27. AEMET. Guía resumida del clima en España 1981-2010, www.aemet.es/es/serviciosclimaticos/datosclimatologi $\cos /$ valoresclimatologicos $? \mathrm{l}=3195 \& \mathrm{k}=\operatorname{mad}($ accessed 20 January 2019).

28. Cohen J. Statistical power analysis for the behavioral sciences. 2nd ed. New York: Academic Press, 1988.

29. Kumar KC, Prasad TR, Ratnam MV and Kamsali N. Fast Fourier Transform power spectrum of radon activity. Radiat Prot Environ 2018; 41: 30-36.

30. Zaini H, Ahmad S and Mohammed K. Determination of radon activity concentration in hot spring and surface water using gamma spectrometry technique. Malay $J$ Anal Sci 2011; 15: 288-294.

31. Salih NF, Jafri ZM and Aswood MS. Measurement of radon concentration in blood and urine samples collected from female cancer patients using RAD7. J Radiat Res Appl Sci 2016; 9: 332-336. 